\title{
Dear Feminist Review,
}

In her article, The Dyke, The Feminist and The Devil, Wendy Clark opened up a number of thorny, horny questions but there is one particular one to which I would like to respond: that is the discussion on what comprises active/passive within sexual relationships.

Through a process of definition, Wendy says the following: 'in heterosexual relationships women are 'passive = receiving', and she then differentiates between heterosexual and lesbian women in this regard. 'In lesbian sex the active is the one giving pleasure to the other as well as possibly obtaining pleasure from the act as well.' So for her the passive becomes active. 'Having pleasure can be an active thing, even though its heterosexual meaning is not that.'

By the stroke of the pen she has excluded the possibility of all heterosexual women from both having and giving pleasure within the sexual act. We are locked into the 'passive = receiving' category from which there is no escape. The logic of this escapes me. As she is not using the terms active and passive within a Freudian context, but rather in a phenomenological, experiential way, how is it that what she says about lesbians and their active/passive situation is their exclusive domain? Why can passive be defined as active through a pleasure principle which is only applicable to lesbian love making? Is she suggesting that heterosexual women have no pleasure in love making with men?

This is not true at all. Sex between men and women does include both active and passive participation for botb partners. If having pleasure is active and giving pleasure is active then many women, by that definition, are active in their sexual relationships with men. To imply that we heterosexual women do nothing other than lie on our backs being penetrated by sadistic men simply is not the case. Such conclusions are erroneously derived from the notion that all men are potential rapists and that all heterosexual relationships involve a cruel raping of female partners.

This effective denial of heterosexual women's active participation in sex has far subtler implications which go beyond the realm of the personal love making situation. Apart from the effect of pre-empting discussions about heterosexual social relationships, it implies that heterosexual feminists can never be true feminists, because they are pursuing relationships with the upholders of the patriarchal system. Lesbian relationships are elevated to a level which can be defined as 'the ideal practice ... free of the worst excesses of the patriarchal heterosexual social system.' In order to proclaim oneself a feminist does it necessitate having a lesbian relationship?

The unintended consequences of this is to marginalize heterosexual women within the feminist movement, many of whom do live in familial situations with male partners and children. It is ironic that this should be the case, that we should experience this isolation inside a movement which proclaims sisterhood.

Perhaps the time has come when the main objectives within the feminist movement need to be reassessed and concepts such as patriarchy and patriarchal relations require re-visiting. The escalating numbers of unemployed, the problems of nuclear warfare, the effects of under-development, all affect us, our partners, be they male or female, and our children. We should be able to bring to these problems the lessons learnt and the understandings gained as feminists.

\section{AnnMarie Wolpe}

